\title{
Stock market reaction to food recalls: a GARCH application
}

\author{
ZIJUN WANG, VICTORIA SALIN*†, NEAL H. HOOKER $\ddagger$ and \\ DAVID LEATHAM* \\ Private Enterprise Research Center, Texas A\&M University, 4231 TAMU, College \\ Station, Texas 77843-4231, USA, *Department of Agricultural Economics, Texas \\ A\&M University, 2124 TAMU, College Station, Texas 77843-2124, USA and \\ $\dagger$ Department of Agricultural, Environmental and Development Economics, The Ohio \\ State University, 323 Agr. Adm., 2120 Fyffe Road, Columbus, Ohio 43210, USA
}

How food recalls due to bacterial contamination affect the stock prices of two companies are examined using a version of the financial market model that accounts for Generalized Autoregressive Conditional Heteroscedasticity (GARCH) effects. GARCH methodology was necessary to uncover the time-varying volatility in the series and it contributed to more efficient econometric results. The initial food recall undertaken by the company is associated with reduced mean returns and higher volatility of the companies studied. Repeated recalls by the same company are not associated with strong reactions. Volatility spillovers across firms suggest potential industry-wide repercussions from bacterial contamination incidents.

\section{INTRODUCTION}

Food safety issues have come to centre stage as contamination incidents worldwide during the 1990s attracted press attention and US policymakers instituted the HACCP (Hazard Analysis Critical Control Point) regulatory process in 1996. One of the hallmarks of the HACCP system is that regulatory requirements are imposed in a general way and firms retain significant responsibility for planning and executing the details of the process control programmes. Given this industry-focused approach, it should be a research priority to understand the full effects of food safety measures on industry.

Recent research has advanced the understanding of the impact on businesses of HACCP adoption (Antle, 2000; Jensen and Unnevehr, 2000; Colatore and Caswell, 2000; and Nganje and Mazzocco, 2000; These studies investigate the costs of HACCP implementation at the firm level and point out the effect on variable and fixed costs from new food quality efforts. Other researchers have considered the consequences businesses face in the event that food contamination reaches consumers. One study of jury awards in product liability claims that result from bacterial contamination of food (Buzby et al. 2001) indicates that the awards tended to be modest, although it should be noted that out-of-court settlement information was not available. Another approach to study the effects of contamination is the model of reputation and quality by Worth (2000), which indicated that outbreaks affecting strawberries were associated with lower prices paid to growers and no change in prices at the retail level. These studies highlight the existence of potential private incentives for firms to invest in food safety. The effectiveness of private incentives should be explored further, given their potential value in complementing government regulatory efforts.

Financial markets are another source of private incentives to promote food safety. Managers of publicly-traded food companies seeking to maximize shareholders' wealth can be expected to align their tactics with the stock market valuation of food safety. One indicator of the market's valuation of food safety is the effect on stock returns associated with specific events of food bacterial contamination. Salin and Hooker (2001) investigated the stock market reaction to four food recalls using an event study

† Corresponding author. E-mail: v-salin@tamu.edu 
approach, which has a long tradition in the finance literature. Salin and Hooker found statistically significant evidence of a negative effect on returns for each of the four recalls considered, over different time frames, and also constructed measures of 'before' and 'after' variability of these stock returns.

While it is interesting to test for financial market reaction to food recalls in this way, the reliability of standard event study procedures bears further scrutiny. The explanatory power of the models used to forecast abnormal returns influences a researcher's ability to distinguish a significant impact in any event study. Therefore, any methodology that can provide a more rigorous specification of the underlying process is likely to permit higher quality conclusions to be drawn from the data. This paper applies such a development in the methodology, compared with that used by Salin and Hooker. The method is a financial market model adjusted for Generalized Autoregressive Conditional Heteroskedasticity (GARCH) properties of the time series of the residuals in the market model. The advantages of the GARCH approach are: first, that estimates are more efficient, leading to better statistical properties; and second, that direct investigation of possible changes in conditional variance of the stock returns is possible, which provides information useful to financial market observers and investors.

\section{METHODOLOGY}

Empirical researchers in financial economics often use Sharpe's (1963) simple market model to investigate the impact of an event on the market value of a publicly traded firm. The market model relates the return on any given security to the return on a market portfolio. For any security $i$ the market model is:

$$
r_{i t}=C_{i}+\phi_{i} r_{m t}+\varepsilon_{i t}
$$

where $r_{i t}$ and $r_{m t}$ are the period $t$ returns on security $i$ and the market portfolio, respectively. In many applications a broad-based stock index such as the Standard and Poor's (S\&P) 500 index is used as a proxy for the market portfolio. $C_{i}$ is a constant; $\varphi_{i}$ is the systematic risk of security $i$; and $\varepsilon_{i t}$ is a disturbance term with zero mean and constant variance.

The parameters of the market model are frequently estimated using an Ordinary Least Squares (OLS) regression. The estimated parameters are then used to calculate abnormal returns associated with the event(s) examined. Clearly such a routine requires strong statistical assumptions. One of these assumptions is that the error term $\varepsilon_{i t}$ is temporally uncorrelated. However, many researchers have questioned this and documented that successive returns on individual stocks are correlated (Lo and MacKinlay, 1988), with large returns (of either sign) that tend to be followed by further large returns (of either sign).
Another assumption of the traditional market model is that the error terms, and hence the returns, follow a normal distribution with constant variance. Error terms from regressions involving stock returns are rarely normally distributed (Fama, 1963). Giaccoto and Ali (1982) have shown that if the assumption of homoscedasticity cannot be satisfied, the standard tests to measure the effect of a specific event on security prices must be adjusted for heteroscedasticity. Otherwise, the parameter estimates may be inefficient and any inferences based upon them will be potentially misleading. Other researchers who came to the same conclusion include Akgiray (1989), Connolly (1989), Corhay and Rad (1994), and Brockett et al. (1999).

Researchers examining food recall effects are interested in forecasting the levels of a series in order to accurately determine if the recall event is associated with a deviation of the returns from their expected path. Accurate estimates of the variance of returns are important for inference about such deviations. In addition, information about changes in volatility of stock returns is important for managers and shareholders, given the role of the risk-return tradeoff in portfolio selection. These reasons underscore the value of econometric modelling that can uncover changes in stock volatility following food recalls. In this research, a GARCH framework of both univariate and multivariate specifications is used to estimate the effects of food recalls on both mean returns and the volatility of those returns. The advantage of GARCH models is that they provide information about the level of the returns series and also its variance. Changes in variance over time are of key concern to this analysis of financial markets, since investors require higher expected returns as compensation for holding riskier assets. Variances that are not constant over time are also important in the validity and efficiency of statistical inference (Hamilton, 1994, p. 657).

\section{TIME SERIES PROCESSES IN EVENT STUDIES}

To generalize the assumption of constant variance required for traditional econometric models, Engle (1982) developed a model describing a new class of stochastic processes called autoregressive conditional heteroscedasticity $(\mathrm{ARCH})$. These are zero mean, serially uncorrelated processes with nonconstant variances conditional on the past, but constant unconditional variances. For such processes, the recent past gives information about the one-period forecast variance. The ARCH model specification has been generalized by Bollerslev $(1986,1987)$ to allow for past conditional variances in the current conditional variance equation. A basic GARCH model consists of a mean equation and a conditional variance equation. The advantage of this approach is that it models the level of the returns $\left(r_{i t}\right)$, as does the basic market model, and also 
allows for time-varying volatility. A modified market model that allows for GARCH processes is specified through additional parameters in the mean equation, and the addition of a variance equation. Equation 1 is extended as a mean equation by adding $\operatorname{lag}(\mathrm{s})$ of the dependent variable to account for possible serial correlation in the series of stock returns:

$$
r_{i t}=C_{i}+\phi_{i} r_{m t}+\sum_{h=0}^{H} \lambda_{h} r_{i, t}-h+\varepsilon_{i t}
$$

The conditional variance equation in the $\operatorname{GARCH}(p, q)$ model is characterized as follows:

$$
\varepsilon_{i t} \mid \Omega_{t} \sim N\left(0, h_{i t}\right), h_{i t}=\alpha_{i 0}+\sum_{k=1}^{q} \alpha_{i k} \varepsilon_{i, t^{-} k}+\sum_{j=1}^{p} \beta_{i j} h_{i, t^{-} j}
$$

where $\Omega_{t}$ is the information set at time $t$ on which the distribution of the errors is assumed to be conditioned, and $\alpha$ and $\beta$ are parameters to be estimated. For $q=0$, the process reduces to the ARCH $(p)$ process; and for $p=q=0, \varepsilon_{i t}$ is simply white noise. The persistence of impacts of shocks on the current volatility of stock returns is measured by the sum of the $\alpha$ 's and $\beta$ 's. Namely, if $\sum_{k} \alpha_{i k}+\sum_{j} \beta_{i j}=1$, then shocks die out very slowly (Engle and Bollerslev, 1986).

Equations 2 and 3 are typically estimated using the maximum likelihood method under the assumption of conditional normality of the residuals. If this assumption does not hold, Bollerslev and Wooldridge (1992) derived a quasi-maximum likelihood method, used in this study, which provides consistent estimates of the covariances and standard errors.

An event study can be conducted using the above model specification by further adding binary variables to the return and variance equations. The use of the binary variables to test for exogenous effects on the time series process follows prior work by several researchers (Choi and Kim, 1991; Crain and Lee, 1996; Shiveley, 1996, and Yang et al., 2001). In this study, a series of dummy variables were included in both the mean and variance equations to mark the timing of the food contamination incidents. It may be expected that adverse information reduces the returns of the stocks and increases the stock return volatility. The extended market model with a $\operatorname{GARCH}(p, q)$ process including the dummies is as follows:

$$
\begin{aligned}
r_{i t}= & C_{i}+\phi_{i} r_{m t}+\sum_{h=0}^{H} \lambda_{h} r_{i, t^{-} h}+\sum_{s=1}^{5} d_{i 1 s} D_{1 s} \\
& +\sum_{s=1}^{5} d_{i 2 s} D_{2 s}+\sum_{s=1}^{5} d_{i 3 s} D_{3 s}+\varepsilon_{i t}
\end{aligned}
$$

$$
h_{i t}=\alpha_{i 0}+\sum_{k=1}^{q} \alpha_{i k} \varepsilon_{i, t^{-} k}+\sum_{j=1}^{p} \beta_{i j} h_{i, t^{-} j}+\sum_{s=1}^{5} d_{i 4 s} D_{4 s}
$$

where $D_{1}$ takes the value 1 two days before the event date and 0 elsewhere; $D_{2}$ equals 1 on the event day and 0 elsewhere; $D_{3}$ equals 1 two days after the event and 0 elsewhere. While $D_{2}$ is used to catch the effect of the event day, $D_{1}$ is meant to summarize the potential for information leakage just prior to the event. $D_{3}$ is used to take into account the possibility that the market may not be fully informed on the day of the announcement. The potential interaction of a recall by the other company is captured in the mean and variance equations by allowing the dummies to equal one for both firms' events. The dummy variable $D_{4}$ in the variance equation is used to assess if there is any change in the stock price volatility - the unsystematic risk of the company - after the recall. These four dummies together describe the potential effect of one recall event on a company's daily return and volatility. In later empirical estimation, a total of 5 recalls will be examined, hence there will be 5 sets of such dummies in (4) and (5), indexed $s=1,2, \ldots, 5$.

While the univariate GARCH model contributes valuable information about the variance effects, if any, for each company that conducted a food recall, a univariate specification does not explicitly address a widely recognized commonality that financial market volatility moves together over time across assets and markets. A multivariate 'M-GARCH' model is therefore a natural extension to account for this correlation in a more systematic way than the dummy variables for cross-firm effects. Haigh and Holt (2000) used such an approach to directly incorporate the time-varying price variances and covariances that characterize the international grain markets. The original development of M-GARCH is due to Engle and Kroner (1993). Using their notation, a vector of variance and covariance for the multivariate GARCH may be specified as:

$$
\operatorname{vech}\left(\Omega_{t}\right)=C+\sum_{i=1}^{q} A_{i} \operatorname{vech}\left(\varepsilon_{t^{-} i} \varepsilon_{t^{-}-i}^{\prime}\right)+\sum_{j=1}^{p} B_{i} \operatorname{vech}\left(\Omega_{t^{-i}}\right)
$$

where $C$ is, the application using 2 firms, a $[2(2+1) / 2] \times 1$, or $3 \times 1$ vector, and $A_{i}$ and $B_{i}$ are both $3 \times 3$ matrices. Obviously, even in this two-dimensional size, the simplest, unrestricted specification of $p=q=1$ involves a total of 21 parameters in the variance equations alone, before any dummy variables are included. For practical purposes, some forms of simplifying assumptions are required of the $A_{i}$ and $B_{i}$ matrices to permit estimation, especially in high dimension models.

In the empirical implementation to measure the effect of recalls within the multivariate framework, both the mean and variance are allowed to be affected by recalls, and also the dummies allowed to enter into the covariance equation. 
This specification permits returns of one company to be affected by its relationships with others in the market, and attempts to isolate the effect of the food recall on the covariance. Specifically, the covariance between two companies' stock returns is a function of its own history and the product of the lagged volatilities of the two stocks.

\section{DATA AND EMPIRICAL FINDINGS}

Food contamination incidents of varying severity affected Sara Lee Corp. and IBP Inc. between 1996 and 2000 (Table 1). To measure possible effects of these recall events on stock returns, the daily closing stock price or index $\left(p_{i t}\right)$ for the two firms and the S\&P 500 index downloaded from http://finance.yahoo.com are used. The data cover a period of five years from 1 January, 1996, to 31 December, 2000. Each of the five events occurred within this sample period. Dividends and stock splits have been incorporated in constructing these series. The actual sample size is 1262 days after removing weekends and holidays.

Table 2 reports summary statistics of the three return series: mean, standard deviation, and skewness. The mean return rates for the three series vary considerably: $2.86 \%$ for IBP Inc. (IBP), $5.89 \%$ for Sara Lee Corporation (SLE), and $6.66 \%$ for the market as proxied by S\&P 500 . While these two food companies performed poorly compared with the market (in the sense of the simple average during the sample period), IBP's average daily return rate is the lowest. As expected because of port- folio effects, the S\&P 500 index has the smallest volatility as measured by standard deviation among the three series. It is also interesting to note that IBP's return was more volatile than SLE's by a margin of $18 \%$ during this 5 -year period, despite the fact that IBP's average return is lower. At this stage, however, it is not clear how much of these differences in return volatilities are attributable to the effects of recall events. The skewness statistics show that all returns of S\&P 500, IBP, and SLE seem to be asymmetrically distributed with the market exhibiting negative skewness, and the IBP and SLE series being biased towards positive returns.

As most statistical results in time series analysis are conditional on stationarity of the fundamental processes, first the properties of each series are investigated. In implementing the augmented Dickey-Fuller test (Dickey and Fuller, 1979), Schwarz's Information Criterion (SIC) was chosen to determine the appropriate lag structure. A maximum of 15 lags in level (or equivalently 14 lags in the first differenced data) was selected. Table 3 reports the unit root test results for the three daily return series with numbers of lag variables determined by minimizing the information criterion. The hypothesis of a unit root in the series is definitely rejected in each case with very low $p$-values (effectively zero). In fact, the unit root hypothesis can be rejected with each of the numbers of lags considered. Not surprisingly, the three closing daily prices (indices) on which these return series are based are found to be nonstationary through the augmented Dickey-Fuller (ADF) test. The results are not reported here in the interests of space.

Table 1. Recalls and stock performance

\begin{tabular}{|c|c|c|c|c|c|}
\hline & \multicolumn{3}{|l|}{ IBP, Inc. } & \multicolumn{2}{|l|}{ Sara Lee } \\
\hline & 1 & 2 & 3 & 1 & 2 \\
\hline Date & 29 April 1998 & 4 Nov. 1998 & 23 June 2000 & 22 Dec. 1998 & 28 Mar. 2000 \\
\hline Product & Ground beef & Ground beef & Ground beef & Hot dogs & Hot dogs \\
\hline Contaminant & E. coli 0157:H7 & E. coli 0157:H7 & E. coli 0157:H7 & Listeria & Listeria \\
\hline Quantity & 282128 pounds & 556226 pounds & 266000 pounds & 15 million pounds & 34500 pounds \\
\hline Stock price change & $-2.92 \%$ & $+2.30 \%$ & $+0.81 \%$ & $+3.28 \%$ & $-1.06 \%$ \\
\hline
\end{tabular}

Table 2. Descriptive statistics for daily stock returns, 1 January 1996 to 31 December 2000

\begin{tabular}{lllcl}
\hline Company Name & Mean & St. dev. & Skewness & Sample size \\
\hline S\&P 500 & 0.0666 & 1.160 & -0.245 & 1262 \\
IBP & 0.0286 & 2.222 & 1.188 & 1262 \\
SLE & 0.0589 & 1.880 & 0.710 & 1262 \\
\hline
\end{tabular}

Note:

a. Daily return rate is measured in percentage points.

b. The skewness of a symmetric distribution is zero. Positive skewness means that the distribution has a long right tail and negative skewness implies that the distribution has a long left tail. 
Table 3. Results from augmented Dickey-Fuller unit root tests

\begin{tabular}{lccc}
\hline & S\&P 500 & IBP & SLE \\
\hline$t$-statistics & $-22.08(2)$ & $-6.00(5)$ & $-27.35(1)$ \\
$1 \%$ critical value (Davidson and MacKinnon, 1993) & -2.56 & -2.56 & -2.56 \\
Effective sample size & 1247 & 1247 & 1247 \\
\hline
\end{tabular}

Note: Numbers in parentheses are lag numbers included in ADF test.

Two decisions had to be made before the GARCH model reported in Equations 5 and 6 could be empirically estimated. First, how many lags of the dependent variables $r_{i t}$ should be included in the return Equation 5 to mitigate serial correlation? Second, what appropriate orders of $\mathrm{ARCH}, p$, and GARCH terms, $q$, should be considered? Lamoureux and Lastrapes (1993), Engle et al., (1993), and West et al. (1993) all provide evidence in support of a simple GARCH $(1,1)$ among a variety of different specifications. Brockett et al. (1999) chose GARCH $(1,1)$ in their modified event study analysis. This literature is followed and only the GARCH $(1,1)$ specification considered in this paper.

While recognizing that standard model selection criteria such as the SIC and Akaike Information Criterion (AIC) have been widely used in the ARCH-GARCH literature, Bollerslev et al. (1988) warned that the statistical properties of these criteria in the ARCH context are unknown. West et al. (1993), and Engle et al. (1993) among others proposed other loss functions but these are typically case specific. The SIC is used here as the criterion for two reasons. First, a popular model selection procedure in the context of ARCH has yet to emerge. Second, major results reached below remain largely consistent under other choices of the lag structure. In Table 4 are reported the SIC statistics for two GARCH models of the IBP and SLE series. No lag, one, two, and three lags are considered.

Models are estimated with RATS programs (Doan, 1996) by maximizing log-likelihood functions. This nonlinear estimation consists of three steps. First, Equation 2 is estimated with OLS assuming constant variance. The OLS estimates are then used as the starting values for second stage estimation using the Simplex method. With the preliminary estimates from the Simplex method, the Broyden-Fletcher-Goldfarb-Shanno (BFGS) algorithm is employed to get both coefficient estimates and corresponding robust standard error estimates. In all cases, convergence is reached within the specified maximum number of iterations. The results using other starting values show that the reported estimates are the ones under which the likelihood functions reach maximum values.

It is interesting to note that SIC unanimously reaches its minimum when no lag is included in estimation for both the IBP and SLE models (Table 4). However, the SICs are extremely close under different assumptions on lag structures. In fact, the parameter estimates are also quite close for different specifications. In Table 4, the Durbin-Watson statistics testing for serial correlation in the residuals are also provided for the models that attain minimum SIC. They are very close to 2 and hence indicate that no further first-order serial correlation exists in the estimated residuals.

Table 5 presents partial parameter estimates of univariate GARCH $(1,1)$ models for IBP and Sara Lee stock returns. The other parameters are not of direct interest and are not reported, but it is worth mentioning that the coefficient of the market proxy S\&P 500 index is highly significant in both models with an estimate of 0.277 and 0.586 , respectively. Three out of the four ARCH and GARCH effects ( $\alpha$ and $\beta$ ) are highly significant, therefore rejecting the constancy of variance and indicating the time varying pattern of stock price variability. This justifies the GARCH specification. In both cases the sum $(\alpha+\beta)$ is less than one, implying the lack of infinite volatility shocks in these stock prices. The sum is 0.511 for the IBP series, showing a relatively slower decay of the conditional variance than in SLE series, which has a sum of 0.229 after a sharp rise due to a significant event such as the recall. This GARCH result may not seem surprising when we remember that IBP's return is more volatile in terms of its sample standard deviation.

Our major interest is to check the sign and significance of the coefficients related to the four dummy variables for the

Table 4. Schwarz Information Criterion values for two univariate GARCH models

\begin{tabular}{lll}
\hline Lag Length & IBP & SLE \\
\hline 0 & $2.5218^{*}$ & $2.1578^{*}$ \\
1 & 2.5270 & 2.1625 \\
2 & 2.5321 & 2.1630 \\
3 & 2.5361 & 2.1686 \\
& & \\
Durbin-Watson statistic & 2.0890 & 1.9952 \\
\hline Note: & & \\
a. Durbin-Watson statistics are given for the model that reaches minimum \\
AIC.
\end{tabular}


Table 5. Univariate $G A R C H(1,1)$ estimation results

\begin{tabular}{|c|c|c|c|c|c|}
\hline & \multicolumn{3}{|c|}{ IBP } & \multicolumn{2}{|c|}{ Sara Lee } \\
\hline & First & Second & Third & First & Second \\
\hline & \multicolumn{5}{|c|}{ IBP } \\
\hline \multicolumn{6}{|c|}{ Mean equation: } \\
\hline$d_{1}$ & $\begin{array}{c}-0.296^{* *} \\
(0.067)\end{array}$ & $\begin{array}{c}-0.096 \\
(1.163)\end{array}$ & $\begin{array}{l}1.474 * * \\
(0.147)\end{array}$ & $\begin{array}{c}0.763^{* *} \\
(0.288)\end{array}$ & $\begin{array}{c}-1.899 * * \\
(0.470)\end{array}$ \\
\hline$d_{2}$ & $\begin{array}{c}-3.166^{* *} \\
(0.087)\end{array}$ & $\begin{array}{l}2.110^{* *} \\
(0.069)\end{array}$ & $\begin{array}{l}1.015^{* *} \\
(0.062)\end{array}$ & $\begin{array}{l}0.441^{* *} \\
(0.095)\end{array}$ & $\begin{array}{c}-1.094 * * \\
(0.071)\end{array}$ \\
\hline$d_{3}$ & $\begin{array}{c}-0.634^{* *} \\
(0.231)\end{array}$ & $\begin{array}{c}-0.315 \\
(0.991)\end{array}$ & $\begin{array}{c}-0.289 \\
(0.430)\end{array}$ & $\begin{array}{c}-0.284 \\
(0.530)\end{array}$ & $\begin{array}{c}-1.372 \\
(3.613)\end{array}$ \\
\hline \multicolumn{6}{|c|}{ Variance equation: } \\
\hline$d_{4}$ & $\begin{array}{l}2.254^{* *} \\
(0.902)\end{array}$ & $\begin{array}{c}-1.872^{* * *} \\
(0.819)\end{array}$ & $\begin{array}{c}0.131 \\
(1.550)\end{array}$ & $\begin{array}{l}2.198^{* *} \\
(0.844)\end{array}$ & $\begin{array}{c}-0.091 \\
(1.052)\end{array}$ \\
\hline$\alpha$ & $\begin{array}{l}0.174^{* *} \\
(0.041)\end{array}$ & & & & \\
\hline$\beta$ & $\begin{array}{l}0.338^{* *} \\
(0.135)\end{array}$ & & & & \\
\hline \multirow[t]{2}{*}{$\alpha+\beta$} & 0.511 & & & & \\
\hline & \multicolumn{5}{|c|}{ SLE } \\
\hline \multicolumn{6}{|c|}{ Mean equation: } \\
\hline$d_{1}$ & $\begin{array}{c}-1.746^{* *} \\
(0.765)\end{array}$ & $\begin{array}{c}-0.057 \\
(0.176)\end{array}$ & $\begin{array}{c}0.655 \\
(0.592)\end{array}$ & $\begin{array}{c}-1.256^{* *} \\
(0.564)\end{array}$ & $\begin{array}{c}-0.694 \\
(1.232)\end{array}$ \\
\hline$d_{2}$ & $\begin{array}{c}0.145 \\
(0.816)\end{array}$ & $\begin{array}{c}-0.614^{* *} \\
(0.123)\end{array}$ & $\begin{array}{c}-0.246^{*} \\
(0.157)\end{array}$ & $\begin{array}{c}0.460 \\
(0.438)\end{array}$ & $\begin{array}{c}-0.437^{*} \\
(0.294)\end{array}$ \\
\hline$d_{3}$ & $\begin{array}{l}0.910^{* *} \\
(0.462)\end{array}$ & $\begin{array}{c}0.078 \\
(0.746)\end{array}$ & $\begin{array}{l}1.940^{* *} \\
(0.863)\end{array}$ & $\begin{array}{c}-0.888^{* *} \\
(0.352)\end{array}$ & $\begin{array}{l}2.975^{* *} \\
(0.529)\end{array}$ \\
\hline \multicolumn{6}{|c|}{ Variance equation: } \\
\hline$d_{4}$ & $\begin{array}{c}0.663^{*} \\
(0.411)\end{array}$ & $\begin{array}{c}0.404 \\
(0.715)\end{array}$ & $\begin{array}{c}-3.581^{*} \\
(1.869)\end{array}$ & $\begin{array}{c}1.284^{*} \\
(0.801)\end{array}$ & $\begin{array}{c}2.610^{*} \\
(1.783)\end{array}$ \\
\hline$\alpha$ & $\begin{array}{l}0.213^{* *} \\
(0.083)\end{array}$ & & & & \\
\hline$\beta$ & $\begin{array}{c}0.016 \\
(0.035)\end{array}$ & & & & \\
\hline$\alpha+\beta$ & 0.229 & & & & \\
\hline
\end{tabular}

Note:

a. Numbers in parenthesis are standard errors.

b. * indicates significant at $15 \%$. ** indicates significant at $5 \%$.

recall events $\left(d_{1}-d_{4}\right)$. In the two mean equations, about two thirds of the estimates are significant at the 0.20 significance level or better. In particular, 10 out of 15 estimates in the IBP mean equation are significant at the 0.05 level, and more than half of the estimates in the SLE mean equation are also significant at this level. The signs on these coefficients present a more mixed picture. A striking feature in the IBP mean equation is that all three dummies have negative signs for the first IBP recall, and all are highly significant. These estimates suggest a negative effect on stock price returns from the initial contamination and recall. Not surprisingly, the dummy for the announcement day $\left(d_{2}\right)$ has the highest value in magnitude (actually among all relevant coefficient estimates considered in this study). In contrast, the effects of the subsequent two recall events are mixed, despite the fact that the second recall was almost twice as severe in terms of quantity affected as the first one. IBP's second recall is associated with negative returns (relative to the market) both before and after the recall was announced, but the effect is positive and is only significant on the event day. The event day dummy for the third recall is also positive and significant (1.015).

There are three possible explanations. The first explanation is a weaker market reaction to the repeated shocks. Put another way, the market might have 'learned' from IBP's initial recall, and had correctly valued the second and third recalls in response to the experience with the first recall. This expectation was incorporated into the market price long before the second and the third recalls were actually announced. The second possible explanation is that the market responded to the next two recalls with lags because of information spread. IBP's stock price decreased moderately following the announcement in both cases, but these reductions in returns were outside 
the event window modelled here. A third explanation is that some other unidentified positive shock(s) to the IBP series may have occurred coincidentally with the second and third IBP recalls.

The significant coefficient estimates associated with the two Sara Lee recalls in the IBP mean equation support the widely held belief that the stock returns of the two meat processing giants interact. Plausible financial reasons exist to explain either positive or negative interactions. A positive cross-effect would indicate that investors shifted their funds into an alternative food company stock when the recall was announced. A nega- tive cross-effect supports a concern that recalls by one company affect the financial status of other firms in the same industry. However, the two recalls had different effects on IBP stock performance. The second Sara Lee recall had significant negative effects while the first one had smaller (in magnitudes), but still significant, positive effects on and before the event day. The changing signs might be the result of market's weaker reaction to repeated shock as before. The first Sara Lee recall was announced the month following the second IBP recall, and the second Sara Lee recall was announced sixteen months after.

Table 6. Bivariate $\operatorname{GARCH}(1,1)$ estimation results

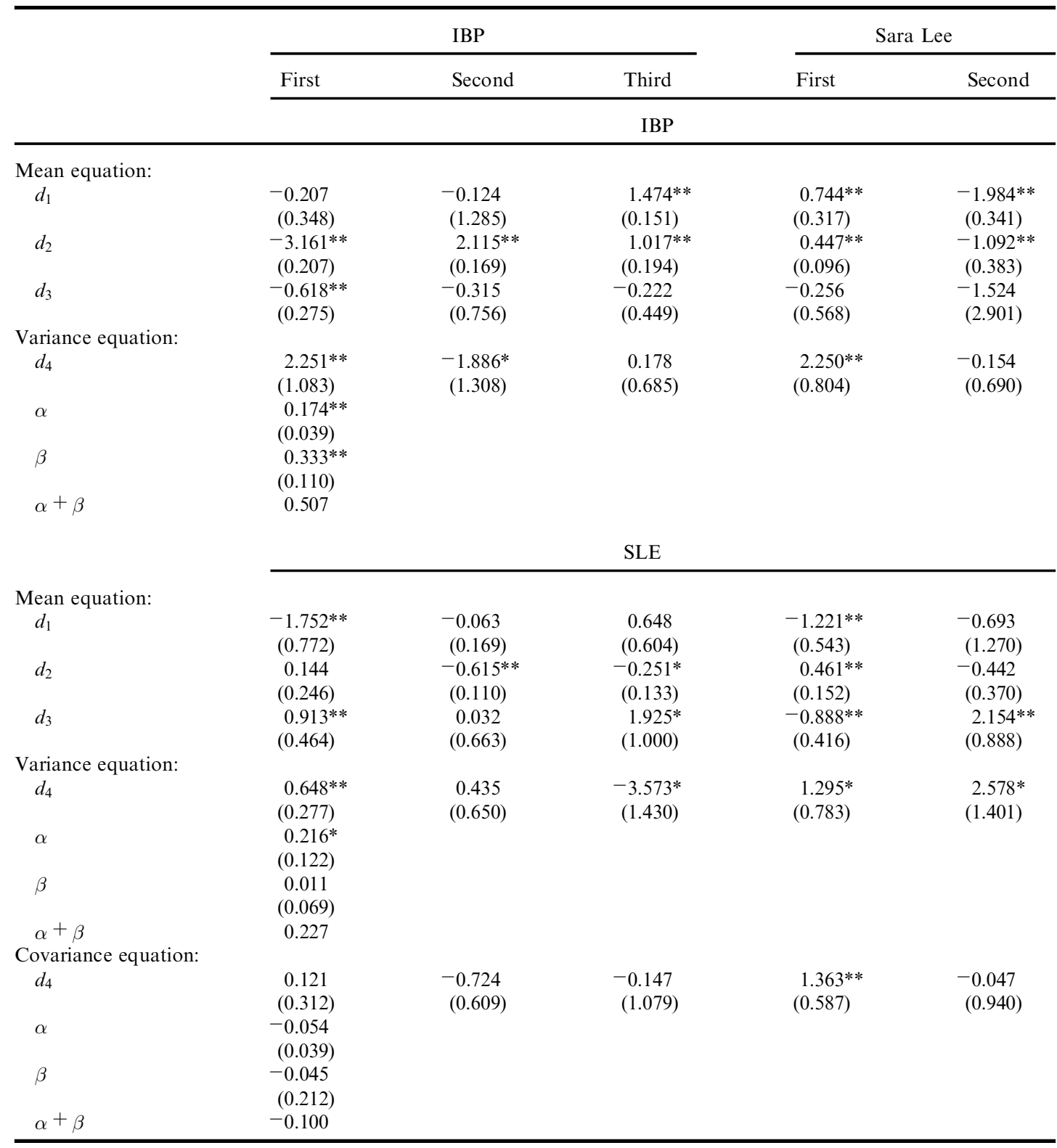

Note:

a. Numbers in parenthesis are standard errors.

b. * indicates significant at $15 \%$. ${ }^{*}$ indicates significant at $5 \%$. 
For Sara Lee Corp., the relatively large, significant and negative estimate of dummy $d_{1}$ of the first Sara Lee recall $(-1.256)$ indicates that there was information leakage before the press notice of the first recall. This initial decline in returns was followed by an insignificant bounce-back (0.460). However, the market corrected its reaction with another moderate drop following the recall $(-0.888)$. As for the impact of the second Sara Lee recall, both $d_{1}$ and $d_{2}$ have negative signs, which is as expected. Again, the market adjusted its valuation of Sara Lee stock after the event. Overall, the first recall had more severe impacts than the second one. This result is consistent with the fact that the first Sara Lee recall was far more severe than any of the other four recalls.

In line with above findings on interactions, the first two IBP recalls had generally negative cross-effects on Sara Lee's stock returns while the impact of IBP's third recall on Sara Lee was not so clear.

As expected, in the two variance equations the first IBP recall and the first Sara Lee recall significantly increased their own stock volatilities in association with food recalls. These share prices are more volatile after the recall. Similar to the pattern in the mean equation, the first IBP recall had a more significant effect than the later recalls. Although positive, the third recall's effect is negligible in terms of both magnitude and significance level. Just like its effect on return, the second IBP recall is associated with decreased volatility, which is a little surprising although one must remember the increased volatility following the first recall. The first IBP recall also increased the volatility of the Sara Lee series, though the effect was not as strong or as significant as the effect associated with the firm's own recall. It is interesting that the estimated effect of the first Sara Lee recall on IBP's volatility was both large and significant (2.198) even though no effect on mean return was observed.

Compared to the univariate specification, the bivariate GARCH utilizes full information from the market in explaining the individual series and hence is anticipated to produce more efficient estimates in general. The use of an explicit covariance equation provides more information about the interaction between these stock returns, and is expected to be an improvement over the univariate estimation. Results in Table 6 confirm the advantage of the bivariate GARCH. Each of the parameter estimates exhibits the same signs as before. Most of them are quite close to the univariate model estimates in magnitudes, but many of them have smaller standard errors, reflecting gains in estimation efficiency.

The parameter estimates for the covariance equation at the bottom of Table 6 indicate the nature of the volatility spillovers is relatively modest. The intercept (not reported in the table) is estimated to be 0.180 and highly significant (the $t$-statistic is 2.335 with a $p$-value of 0.019 ), and the two $\mathrm{ARCH}$ and GARCH parameters are quite small and insig- nificant. This implies that the relationship between the two companies' stock returns was quite stable during the sample period. With the exception of the first Sara Lee recall, the recall events from IBP and Sara Lee did not seem to have much impact on the relationship with the dummy estimates being generally insignificant. The corresponding estimate is 1.363 and is significant at a level of 0.02 .

\section{CONCLUSIONS}

This study investigates the effects of five food recalls on the stock returns of two affected companies within a GARCH framework. The assumption of constant conditional variance is clearly rejected in all cases, which justifies the use of GARCH in this context. The empirical results from both univariate and bivariate estimations also indicated that, for both companies, the first recalls had significantly negative effects on daily returns around the event dates. In addition, the first recalls not only significantly increased the volatilities of their own companies' stock returns, but also those of the other company in the same industry.

The evidence of additional risks from subsequent recalls is, in general, much weaker. Results from the bivariate GARCH model show that the two meat-processing giants have enjoyed a fairly stable relation in their stock market returns. The first Sara Lee recall is the most severe among all major meat product recalls; it is the only recall that significantly strengthened the stock correlation between IBP and Sara Lee. This finding suggests that the market may be taking into account the severity of food recall events. The major results reported in this study are robust to choices of different lag orders about the underlying processes, and different sample periods used to estimate the model.

While the GARCH modelling strategy has received a lot of attention in financial studies, the authors are not aware of any empirical work that has applied GARCH to assess the effect of food recalls on firms' stock performance. The interesting results from both univariate and bivariate GARCH specifications convinced us that the GARCH model is a promising approach to financial event studies. Taking into account interactions among firms in the same industry, the multivariate GARCH model provides more efficient estimates than the univariate approach, and explicitly models the spillover effects among different companies.

While the estimation of the bivariate GARCH was tractable in this examination of two firms, it should be noted that multivariate GARCH systems in higher dimensions can present difficulties to the econometrician. At the very least, pair-wise comparisons of firms would be feasible, if 
more recall events by publicly traded firms were to be considered.

The reaction of investors to food recalls by two large firms suggests a role of financial markets in providing private-sector incentives to promote food safety. The value of the firms fell initially, but not in subsequent events, which implies that risks related to recalls were anticipated by investors once the market became sensitized to food safety issues.

\section{REFERENCES}

Akgiray, V. (1989) Conditional heteroskedasticity in time series of stock returns: evidence and forecasts, Journal of Business, $\mathbf{1}$, $55-80$.

Antle, J. M. (2000) No such thing as a free safe lunch: the cost of food safety regulation in the meat industry, American Journal of Agricultural Economics, 82(2), 310-22.

Bollerslev, T. (1986) Generalized autoregressive conditional heteroskedasticity, Journal of Econometrics, 31, 307-27.

Bollerslev, T. (1987) A conditionally heteroskedastic time series model for speculative prices and rates of return, Review of Economics and Statistics, 69, 542-47.

Bollerslev, T., Engle, R. F. and Wooldrige, J. M. (1988) A capital asset pricing model with time varying covariances, Journal of Political Economy, 96, 116-31.

Brockett, P. L., Chen, H. M. and Garven, J. R. (1999) A new stochastically flexible event methodology with application to Proposition 103, Insurance, Mathematics, and Economics, 25, 197-217.

Buzby, J. C., Frenzen, J. D. and Rasco, B. (2001) Econometric research service agricultural Economic Report No. 799, Product Liability and Microbial Foodborne Illness, 27 May, Food and Rural Economics Division, United States Department of Agriculture. http://www.ers.usda.gov/publications/aer799.

Choi, S. and Kim, B. J. C. (1991) Monetary policy regime changes and the risk premium in the foreign exchange markets: A GARCH examination, Economics Letters, 37, 447-52.

Colatore, C. and Caswell, J. A. (2000) The cost of HACCP implementation in the seafood industry: a case study of breaded fish, in The Economics of HACCP: New Studies of Costs and Benefits (Ed.) L. J. Unnevehr, Eagan Press, St. Paul, MN, Chapter 4.

Connolly, R. A. (1989) An examination of the robustness of the weekend effect, Journal of Financial and Quantitative Analysis, 24, 133-69.

Corhay, A. and Rad, A. T. (1994) Statistical properties of daily return: evidence from European stock markets, Journal of Business Finance and Accounting, 21, 271-82.

Crain, J. and Lee, J. H. (1996) Volatility in wheat spot and futures markets, 1950-1993: government farm programs, seasonality, and causality, Journal of Finance, 51, 325-343.

Davidson, R. and MacKinnon, J. G. (1993) Estimation and Inference in Econometrics, Oxford University Press, Oxford.
Dickey, D. A. and Fuller, W. A. (1979) Distribution of the estimators for autoregressive time series with a unit root, Journal of the American Statistical Association, 77, 427-31.

Doan, T. A. (1996) RATS 4.0, Estima, Evanston IL.

Engle, R.F. (1982) Autoregressive conditional heteroskedasticity with estimates of the variance of UK inflation, Econometrica, 50, 987-1008.

Engle, R. F. and Bollerslev, T. (1986) Modeling the persistence of conditional variances, Econometric Reviews, 5, 1-50.

Engle, R. F. and Kroner, K. F. (1993) Multivariate simultaneous generalized ARCH, Econometric Theory, 11, 122-50.

Engle, R. F., Hong, T., Kane, A. and Noh, J. (1993) Arbitration valuation of variance forecasts using simulated options markets, Advances in Futures and Options Research, 6, 393-15.

Fama, E. F. (1963) Mandlebrot and the stable paretian hypothesis, Journal of Business, 36, 420-29.

Giaccoto, C. and Ali, M. M. (1982) Optimal distribution free tests and further evidence of heteroskedasticity in the market model, Journal of Finance, 37, 1,247-57.

Haigh, M. S. and Holt, M. T. (2000) Hedging multiple price uncertainty in international grain trade, American Journal of Agricultural Economics, 82(4), 881-96.

Hamilton, J. D. (1994) Time Series Analysis, Princeton University Press, pp. 657.

Jensen, H. H. and Unnevehr, J. L. (2000) HACCP in pork processing: costs and benefits, in The Economics of HACCP: New Studies of Costs and Benefits (Ed.) L.J. Unnevehr, Eagan Press, St. Paul, MN, Chapter 3.

Lamoureux, C. G. and Lastrapes, W. D. (1993) Forecasting stock return variance: toward an understanding of stochastic implied volatilities, Review of Financial Studies, 5, 293-326.

Lo, A.W. and MacKinlay, A. G. (1988) Stock market prices do not follow random walks: evidence from a simple specification test, Review of Financial Studies, 1, 41-66.

Nganje, W. E. and Mazzocco, M. A. (2000) Economic efficiency analysis of HACCP in the US red meat industry, in The Economics of HACCP: New Studies of Costs and Benefits (Ed.) L. J. Unnevehr, Eagan Press, St. Paul, MN, Chapter 15.

Salin, V. and Hooker, N. H. (2001) Stock market reaction to food recalls, Review of Agricultural Economics, 23(1), 33-46.

Sharpe, W. F. (1963) A simplified model for portfolio analysis, Management Science, 9, 277-93.

Shively, G. (1996) Food price variability and economic reform: an ARCH approach for Ghana, American Journal of Agricultural Economics, 78(1), 126-36.

West, K. D., Edison, H. J. and Cho, D. (1993) A utility based comparison of some models of foreign exchange volatility, Journal of International Economics, 35, 23-46.

Worth, T. W. (2000) The cost of an outbreak in the fresh strawberry market, The Economics of HACCP: New Studies of Costs and Benefits (Ed.) L. J. Unnevehr, Eagan Press, St. Paul, MN, Chapter 12.

Yang, J., Haigh, M. S. and Leatham, D. J. (2001) Agricultural liberalization policy and commodity price volatility: a GARCH application, Applied Economics Letters, 8(9), 59398. 